\title{
Thulu Thu Thu - Before the Sun Harms You. Sonic and Haptic FORMS OF SOLIDARITY IN ENVIRONMENTAL SPECTRALITIES
}

knowbotiq $^{1}$

The artist duo knowbotiq were invited in 2019/20 by the Timespan Heritage and Art Center in the Scottish Highlands to develop a project on the ecologies of the peat bogs. The resulting project, "Thulu thu thu, before the sun harms you", traced and unfolded past, present and future entanglements and narratives of materialities in the peat land, it's inscribed asymmetric violence and the impacts of racialized capitalism. The artistic unfolding of the land developed performative acts of "collective sensing"- groups of people connected through a multitudinous object of braided plant fibers (Thulhu) to apprehend the vibrations of the peatlands. Their explorations were accompanied by "sonic incantations" - knowbotiq invited other artists for producing a fractured series of sounds, songs and readings. The incantations were articulated from various planetary positions, invoking the inhumane politics of the Anthropocene.

Keywords: peat bogs, carbon sinks, incantations, collective sensing, molecular intimacies

1 Knowbotiq (Yvonne Wilhelm, Christian Huebler) in collaboration with Lamin Fofana, Ayesha Hameed and Elvin Brandhi, Fundación Mareia, Margarida Mendes, Pedro Neves Marquez and Raw Forest, Odete, Romy Rüegger. The sensing processes and the incantations formed together with lectures in the open field the symposium, Molecular Intimacies, organized by Sadie Young, director of the Timespan Art Center and knowbotiq, held end of January 2020. Authors' contact: studio@knowbotiq.net 


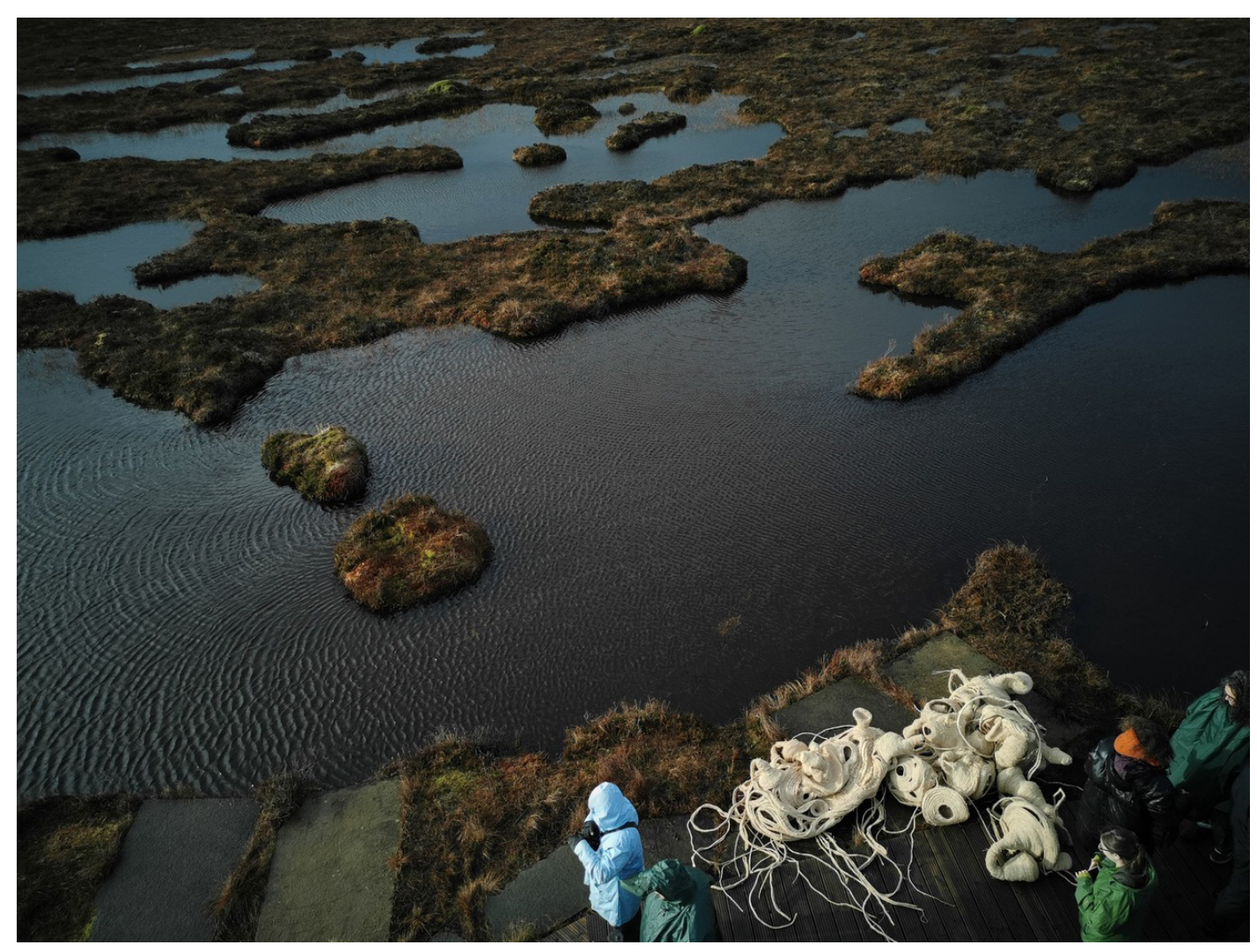

Thulhu Thu Thu, before the sun harms you, knowbotiq 2020: Bog sensing.

The peat bogs in the Scottish Highlands are a critical zone of capitalist modernism which have memorialized the 'developmental' logic of colonialism and are perpetuating its language of growth, extraction, exploitation and profit accumulation. During the "Highland Clearances" in the $18^{\text {th }}$ and $19^{\text {th }}$ centuries feudal landlords, enriched from their profits on colonial plantations, forced crofters off their land. They moved them to newly built fishing villages on the coast or to the colonies in Guyana, Jamaica, India and Canada. The large moorland areas got drained, afforested and converted into sheep grazing and deer stalking territories. Today a spaceport is being built to launch satellites from North Sutherland; oversized wind farms generate lucrative returns for foreign landowners; the powerful economic body of the white Scottish ancestry industry encourages a cleansing of Scotland's imperial history and mandatory policies sanction forced migration from socially disadvantaged urban areas into the remote Highlands.

The following artistic writing is a poetic rendering of a 3 day long collective encounter in the peat bogs during the field symposium. The rhythm of the words in resonance with the embedded sounds of the incantations are reverberations of the affects and experiences in a deep carbon-based techno-ecology, a land dedicated to be cultivated by non-humans. The embedded incantations can be listened at: http://knowbotiq.net/incantations/

\section{Sensing Molecular Intimacies}

Crossing the flow country in the Scottish Highlands, a large expanse of blanket bog, leaving behind tourist projections, ignoring data nature and its myths of the pristine. 
Listening and invoking,

breathing with the bogs -

what a calming, post-glacial hilly landscape.

Exploring how intensively unspectacular

other worldings.

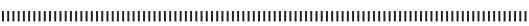

Track 1: Inscription by Lamin Fofana

https://archive.org/download/ThuluThuThu/Track01.mp3

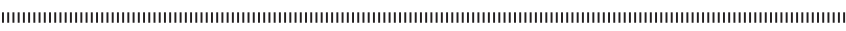

She jumps. Leap from me. Then I decide to count the endless names of stones. Rock leap, wall heart, rip eye, cease breadth, marl cut, blood leap, clay deep, coal dead, coal deep, never rot, never cease, sand high, bone dirt, dust hard, mud bird, mud fish, mud word, rock flower, coral water, coral heart, coral breath. Brand (1996: 241-42, 246-47)

Large parts of the land,

efficient storages, carbon sinks,

currently re- and denaturalized.

Molecularly repaired, restored, conserved.

The bogs register and cannibalize

sedate and rapid transformations

local and planetary environmental policies.

Circulating decay and energy across geological epochs, the land mainly composed

from a subterranean system.

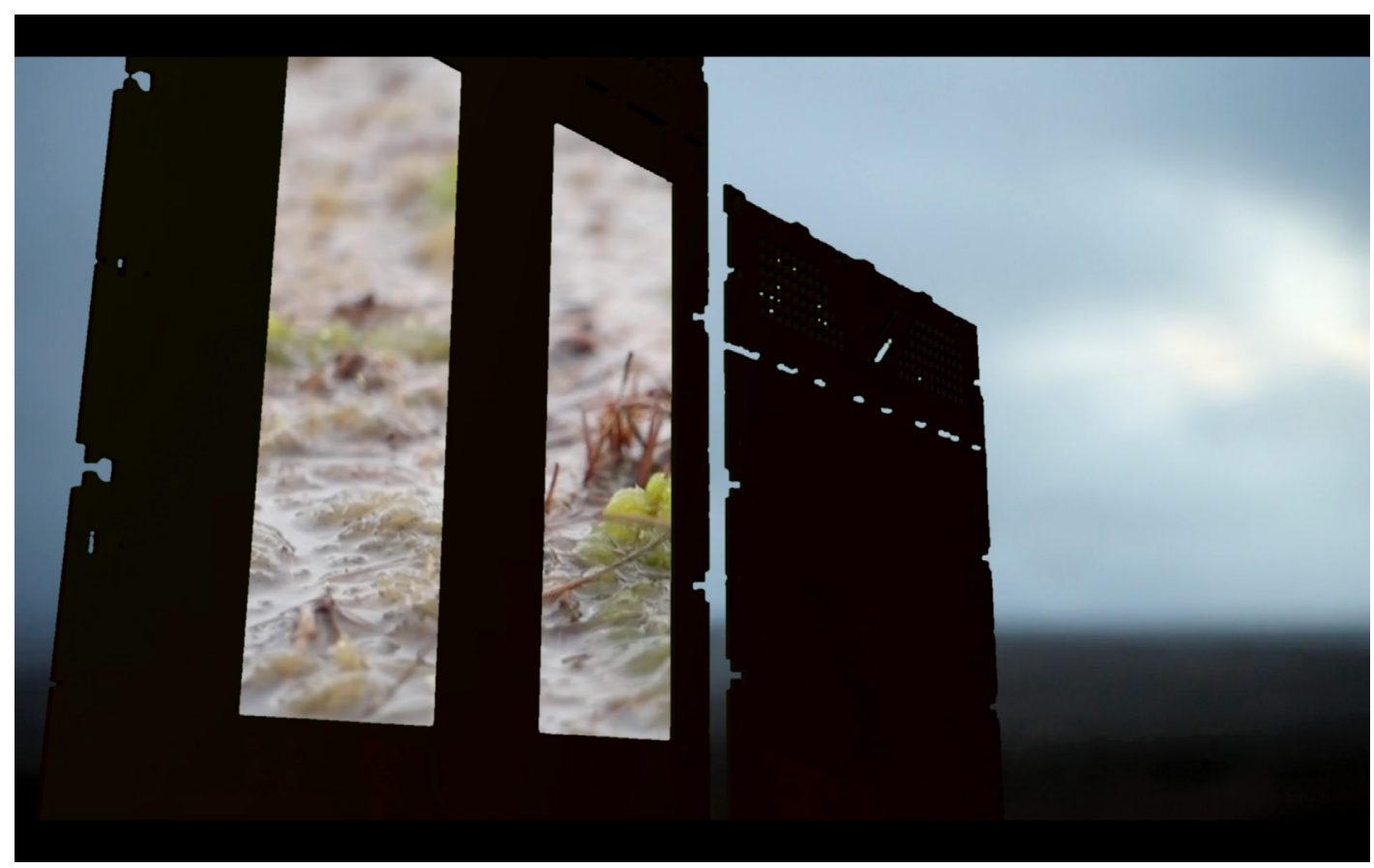

Thulhu Thu Thu, before the sun harms you, knowbotiq 2020: Metabolism of mosses. 
Sphagnum mosses carpets

thousands of years

conserving water and nutrients.

Non-life forming life

The metabolic processes of the mosses

to recite matter and disturb time.

Where human memory fails in anaerobic layers.

Cybernetic measuring, precisely dated, nuclear particles, volcanic ash and acid rain.

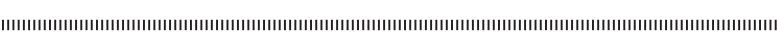

Track 2: Seafixation by Ayesha Hameed/Elvin Brandhi

https://archive.org/download/ThuluThuThu/Track02.mp3

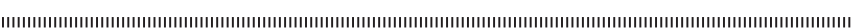

And I mean unearthly because evil earth, its soil is stolen and its body is in the service of a soil, that loses and loses and loses. Hameed

Layers of monstrous molecular intimacies

crisscrossed by voidings and extractive valorizations.

Scars of human peat cuttings,

perfect unearthly territories

to imagine or to speculate on future extinction.

Planetary limits.

Here, the ghosts of the white Anthropocene

preserved in deep time

rendered inhuman materialities of the earth.

The darkness of the peatland pulsating.

How to encounter

the vibrating land without appropriation?

The contagious sting of a mosquito

embodied a drone sound.

Feeling the clap of the wings.

A western body conditioned through thinking in forms

Orientations through central perspective

now, just longing for the subterranean.

Imagining the land as molecules permanently contacting.

Haptic touch.

Do those molecules feel addressed?

Are they willing to respond?

They do send waves, 
each moment a rapport,

relays of carbon interferences.

The sounds of mud soaking boots.

Human bodies entering trance.

How to become a collective body?

A mantra smoothening the frightening solitude, humming the beloved to sleep.

Holding overtones

infra-spaces, more than human bodies,

vibrations, exchange.

Are these oscillations forms of knowing?

Like incantations, chanted spells recorded in Gaelic Grimoires

serving supranatural powers while stoking the fire, smelling the peat.

Invocations, carbon-based earthly soundings.

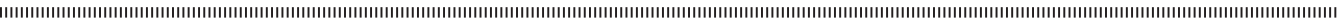

Track 3: Tropical Poltergeist (for Adam and Zach Kahlil) by Pedro Neves Marquez/Raw Forest https://archive.org/download/ThuluThuThu/Track03.mp3

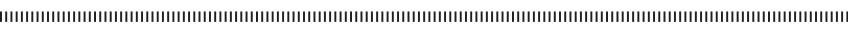

About endings. This one isn't mine. Who is it by? Apocalypse is history's memory. I can't remember.

Neves Marquez

Deconstructing the visual semiotics of the land

or as Adrian Piper puts it,

overriding Western "visual pathology".

There is no way to represent the presence of the molecular.

Listen to the land, Tina Campt contributes,

"Every sound consists of more than what we hear".

Inserting a hydrophone into the bog

modest murmurings.

Modelling the rhythms and dynamics of recorded data.

As it happened in 1967,

when Jocelyn Bell proved the existence;

Pulsating sources of radio emission

out of a 30-meter-long data sheet

indicating an invisible, fast rotating neutron star.

What are the bogs telling us?

The small colorful leaves of the sphagnum mosses

reflected on water surface

Subtle swinging of grass. 
Invocation, a gentle deep sound.

Fred Moten -such sounds require the kind of listening

that activate rather than fragment.

Challenging and evoking.

Silence of molecularized land.

Conjuring, sensing, allowing, noticing, responding.

The surface of the brittle raffia

caresses our fingertips,

emptying imaginations, invoking textures.

Trans temporalities

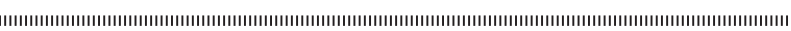

Track 4: Entrega Sonora by Fundaciòn Mareia (excerpt)

https://archive.org/download/ThuluThuThu/Track04.mp3

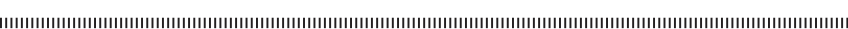

The slow and fast weather, the rain that wets us like tears of joy, invites us to recognize the spaces where the colors inspire us, and the singing of the voices are part of what we call music. We re-signify our biocultural territories with our existence. Fundación Mareia

More groups of sentients to relate to, embodying the situational tremor, blind strolling of people.

Submerging, response-able joy of devastation?

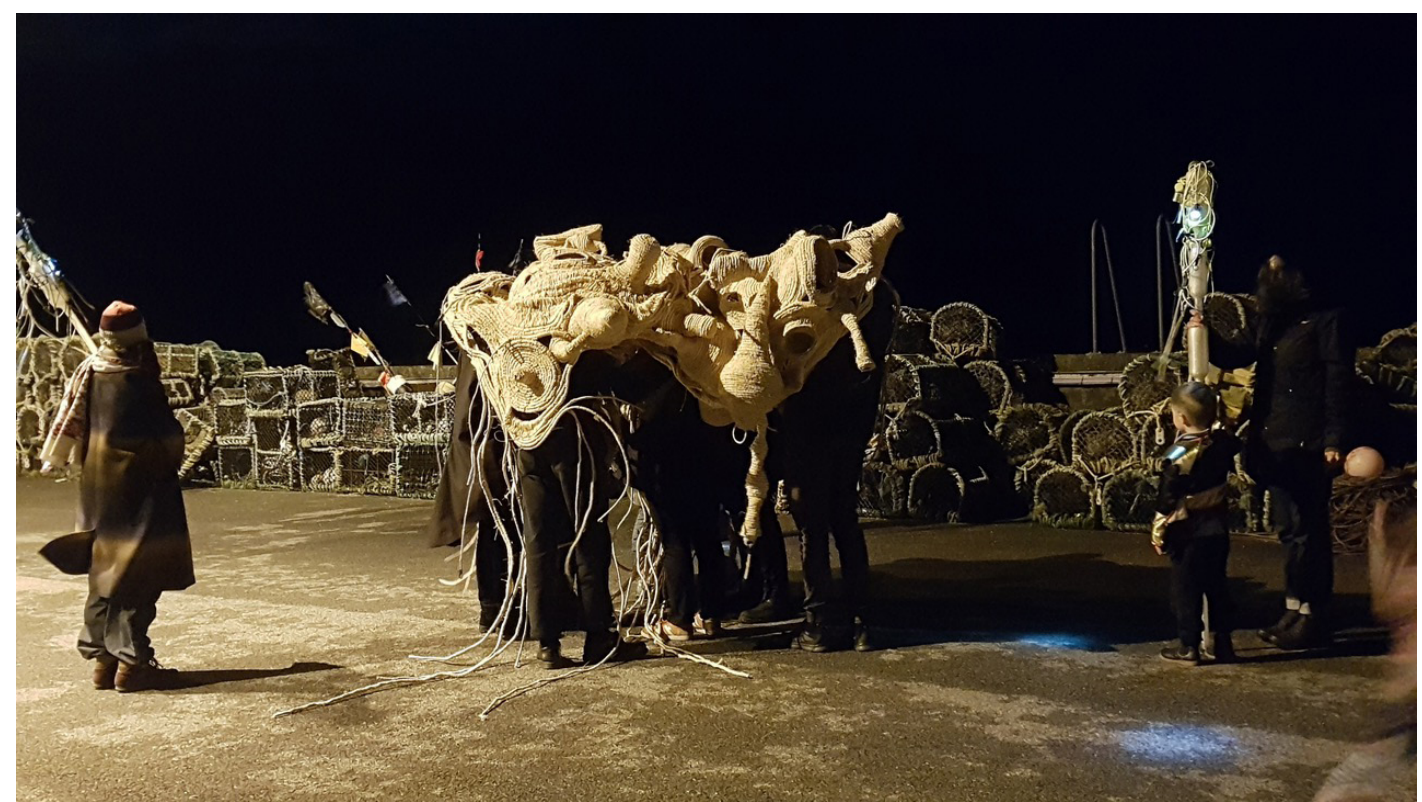

Thulhu Thu Thu, before the sun harms you, knowbotiq 2020: Collective body.

Thulu, a manifold being

eluding apprehension.

Fibers from raffia, an African palm tree, 
turning matter into care,

Thulhu thu thu

Months of collective weaving and knotting. undefined, form/less.

It bears the traces of a Berlin backyard studio

and the stories of the weavers.

It smells of its use in the moors, micro doses.

Grains of sand from Dounreay nuclear beach, interspersed with nitrate-rich weeds of a structurally weak German land awaiting activation at mercury-contaminated Rio Atrato.

Openings for cosmopolitical relations?

Waiting to be invoked

You want to become part of it, to preserve it, relay of intimate respect

Thulhu thu thu

Before the sun harms you.

\section{ARTISTS' BIOGRAPHIES}

Lamin Fofana is an electronic producer, DJ and artist. His instrumental electronic music contrasts the reality of our world with what's beyond and explores questions of movement, migration, alienation, and belonging. He runs the Sci-Fi \& Fantasy label which links techno back to the real world, to bridge aesthetics with socioeconomics, with ocean currents, with stale bread and dirty water.

Fundación Mareia, a women's collective of artists/humanists who work with participatory research-action with a focus on race, gender, environmental and sonic-embodiment. Mareia enact art as a vehicle of social transformation, for a revitalization of ancestral practices/knowledges through ethno-educative and emancipatory methodologies, and of holistic healing that empowers the resilience and dignity of the Colombian Pacific.

Ayesha Hameeds moving image, performance and written works explore contemporary borders and migration, critical race theory, Walter Benjamin and visual cultures of the Black Atlantic. Her projects Black Atlantis and A Rough History (of the destruction of fingerprints) have been performed and exhibited internationally. She is the co-editor of Futures and Fictions (Repeater 2017) and is currently the Program Leader for the MA in Contemporary Art Theory in the Department of Visual Cultures at Goldsmiths University of London.

Elvin Brandhi is an improvising lyricist, producer and sound artist from Bridgend Wales, making auto-tune blast beats from field recordings, tapes, instruments and voice. Live shows are unyielding bursts of erupting animation where her caustic stream of consciousness cavorts 
with restless, glitched out heaviness. Other main projects include Yeah You, INSIN in collaboration with Bashar Suileman.

Pedro Neves Marques is a visual artist, filmmaker, and writer. Born in Lisbon, Portugal, he lives in New York since 2012. Often based in Brazil, his work ranges from fiction, in the form of narrative films and short stories, to theoretical writings between art, cinema, and anthropology. Heavily influenced by cosmopolitics and feminist historians of science, his stories highlight the clash between disputing images of nature, technology, and gender. In all of them, science fiction is the key to thinking through both past histories of colonization and the possibility of non-Western futures.

Raw Forest is one of Margarida Magalhães' alter-egos that was born around 2010 in cybernetic space. Lately, her work has been manifesting itself mostly through sound - creating landscapes and environments by the means of immersive electronic music. Her landscapes arise from the ruins of past digital utopias and her music has been more and more influenced by this environment of disillusion and collapse, shaped by the present dystopian scenery.

Margarida Mendes is an educator, curator, and activist living and working in Lisbon, and a member of the Oceano Livre environmental movement. Exploring the overlap between cybernetics, philosophy, ecology, and experimental film, her research investigates the dynamic transformations of the environment and their impact on societal structures and cultural production. She has directed several educational platforms such as escuelita, an informal school at Centro de Arte Dos de Mayo, Madrid (2017) and The Barber Shop project space in Lisbon dedicated to transdisciplinary research (2009-16). She was part of the curatorial team for the 11th Gwangju Biennale (2016) and the 4th Istanbul Design Biennale (2018). In 2016 she curated the long-term research exhibition MATTER FICTIONS at Museu Berardo, Lisbon. She is a $\mathrm{PhD}$ candidate at the Centre for Research Architecture.

Odete is a performer, writer, visual artist and DJ who uses her own life-particularly her experience as a trans woman-as material for her practice. Her DJ sets draw out the relationships between different points in queer music history using vogue claps, punk screams and diva vocals, pop, politics and erratically pounding beats.

Romy Ruegger develops performances, audio works and writings that consider how we move and communicate in social space, and the institutions and structures that control and restrict these actions. Her work is often site-specific and made in collaboration with other artists, creating sites of shared listening, encounter and unlearning that counter accepted narratives and value systems.

knowbotiq (Yvonne Wilhelm, Christian Huebler, http://knowbotiq.net, http://knowbotiq. net/thulhu/). The artist duo_experiments with forms and medialities of knowledge, political representations, and epistemic disobedience. In various installations, projects on art, public and performative settings, knowbotiq explore molecular, psychotropic and derivative aesthetics. knowbotiq has participated in the Venice Biennale, Moscow Biennale, Seoul Biennale,Hongkong Shenzen Biennale, Biennale Rotterdam, and exhibited in New Museum New York, Witte de With Rotterdam, MOCA Taipeh, Kunsthalle St. Gallen, Wilhelm Lehmbruck Museum, Skuc Gallery Ljubljana, NAMOC Beijing, Arhus Kunstmuseum, Museum of Contemporary Art 
Helsinki, Hamburger Kunstverein, Henie Onstad Kunstsenter Oslo, Museum Ludwig Köln and has a professorship at the MFA program, University of the Arts Zurich.

\section{REFERENCES}

Brand, Dionne. 1996. In Another Place, Not Here. Toronto: Vintage Canada. John B. Bowles. 2011. Adrian Piper - Race, Gender, And Embodiment. Durham, N.C.: Duke University Press.

Campt, Tina. 2017. Listening to Images. Durham, N.C.: Duke University Press.

Moten, Fred. 2003. In the Break: The Aesthetics of the Black Radical Tradition. Minneapolis, London: University of Minnesota Press.

Date received: 2020-07-31

Date accepted: 2021-03-03 